\title{
Nicotinic modulation of cortical circuits
}

\section{Sergio Arroyo ${ }^{\dagger}$, Corbett Bennett ${ }^{\dagger}$ and Shaul Hestrin*}

Department of Comparative Medicine, Stanford University School of Medicine, Stanford, CA, USA

\section{Edited by:}

Allan T. Gulledge, Geisel School of

Medicine at Dartmouth, USA

Reviewed by:

Bruno Cauli, CNRS and UPMC, France

Randy M. Bruno, Columbia University,

USA

${ }^{*}$ Correspondence:

Shaul Hestrin, Department of

Comparative Medicine, Stanford

University School of Medicine,

Edwards R314, 300 Pasteur Drive,

Stanford, CA 94305, USA

e-mail: shestrin@stanford.edu

tThese authors have contributed

equally to this work.
The ascending cholinergic neuromodulatory system sends projections throughout cortex and has been shown to play an important role in a number of cognitive functions including arousal, working memory, and attention. However, despite a wealth of behavioral and anatomical data, understanding how cholinergic synapses modulate cortical function has been limited by the inability to selectively activate cholinergic axons. Now, with the development of optogenetic tools and cell-type specific Cre-driver mouse lines, it has become possible to stimulate cholinergic axons from the basal forebrain (BF) and probe cholinergic synapses in the cortex for the first time. Here we review recent work studying the cell-type specificity of nicotinic signaling in the cortex, synaptic mechanisms mediating cholinergic transmission, and the potential functional role of nicotinic modulation.

Keywords: cholinergic, nicotinic receptors, interneuron, volume transmission, optogenetics

\section{INTRODUCTION}

Cholinergic axons from the basal forebrain (BF) innervate the entire cortex and are the main source of cortical acetylcholine (ACh; Mesulam et al., 1983; Rieck and Carey, 1984; Rye et al., 1984; Saper, 1984; Eckenstein et al., 1988). Endogenously released ACh activates both metabotropic muscarinic and/or ionotropic nicotinic acetylcholine receptors (nAChRs) expressed on cortical neurons. In this review, we will focus on $\mathrm{nAChR}$ activation in the cortex.

Nicotinic receptors are pentameric proteins comprised of particular combinations of subunits $\alpha 2-\alpha 7$ and $\beta 2-\beta 4$ (CorderoErausquin et al., 2000; Dani and Bertrand, 2007). In the cortex, two main types of nAChRs predominate: the low affinity homomeric $\alpha 7$ receptor and the high affinity heteromeric $\alpha 4 \beta 2$ receptor, though the $\alpha 5$ subunit is expressed to a lesser extent as well (Winzer-Serhan and Leslie, 2005; Kassam et al., 2008). Because these receptors exhibit distinct cationic permeabilities, agonist affinities, and desensitization properties (Dani and Bertrand, 2007), phasic activation of cholinergic BF axons can produce a temporally complex pattern of nAChR-dependent activation in cortical neurons depending on the identity and proportion of receptor subtypes being expressed.

\section{CELL-TYPE SPECIFICITY OF NICOTINIC RECEPTOR EXPRESSION}

Several studies applying exogenous cholinergic agonists have demonstrated that only a fraction of cortical cells express functional nAChRs (summarized in Figure 1). In the supragranular layers, nicotinic receptors are expressed exclusively in inhibitory cells, including all L1 interneurons (Christophe et al., 2002; Gulledge et al., 2007) and a heterogeneous subset of L2/3 interneurons that co-express one or more of the following biochemical markers: vasoactive intestinal peptide
(VIP), cholecystokinin, calretinin, calbindin, and neuropeptide Y (Porter et al., 1999; Gulledge et al., 2007). However, in two of the most prominent classes of inhibitory cells, parvalbumin (PV)-expressing and somatostatin (SOM)-expressing interneurons, $\mathrm{nAChR}$ expression is either absent or sparse (Porter et al., 1999; Gulledge et al., 2007). Interestingly, many if not all nAChR-expressing interneurons also express the ionotropic serotonergic receptor (5HT3, Férézou et al., 2002; Lee et al., 2010). Given that cholinergic cells in the BF and serotonergic cells in the raphe nucleus are both more active during wakefulness than during non-rapid eye movement sleep (Wu et al., 2004; Lee et al., 2005), the cortical targets on which these neuromodulatory systems converge may play a role in producing the pattern of activity associated with wakefulness.

Less is known about the pattern of nAChR expression in the lower cortical layers. Nicotinic receptors are expressed presynaptically on thalamocortical axons in L4 (Gil et al., 1997; Disney et al., 2007) where they have been shown to enhance sensory responses (Disney et al., 2007). In L5, nicotinic responses have been reported in low-threshold spiking (LTS; Xiang et al., 1998; but see Porter et al. (1999); Gulledge et al. (2007)) but not fast-spiking (FS) interneurons (Xiang et al., 1998; Porter et al., 1999; Gulledge et al., 2007). Thus, in both supra- and infragranular cortex PV+ interneurons do not exhibit postsynaptic nicotinic responses, suggesting that some rules for $\mathrm{nAChR}$ expression in GABAergic cells may be shared between the upper and lower layers (Gulledge et al., 2007). Interestingly, in contrast to pyramidal cells in the supragranular layers, nicotinic responses have been demonstrated in L6 pyramidal neurons (Kassam et al., 2008) and L5 pyramidal neurons (Zolles et al., 2009; Poorthuis et al., 2013), although responses in L5 pyramidal neurons have not been universally reported (Porter et al., 1999; Gulledge et al., 2007). 


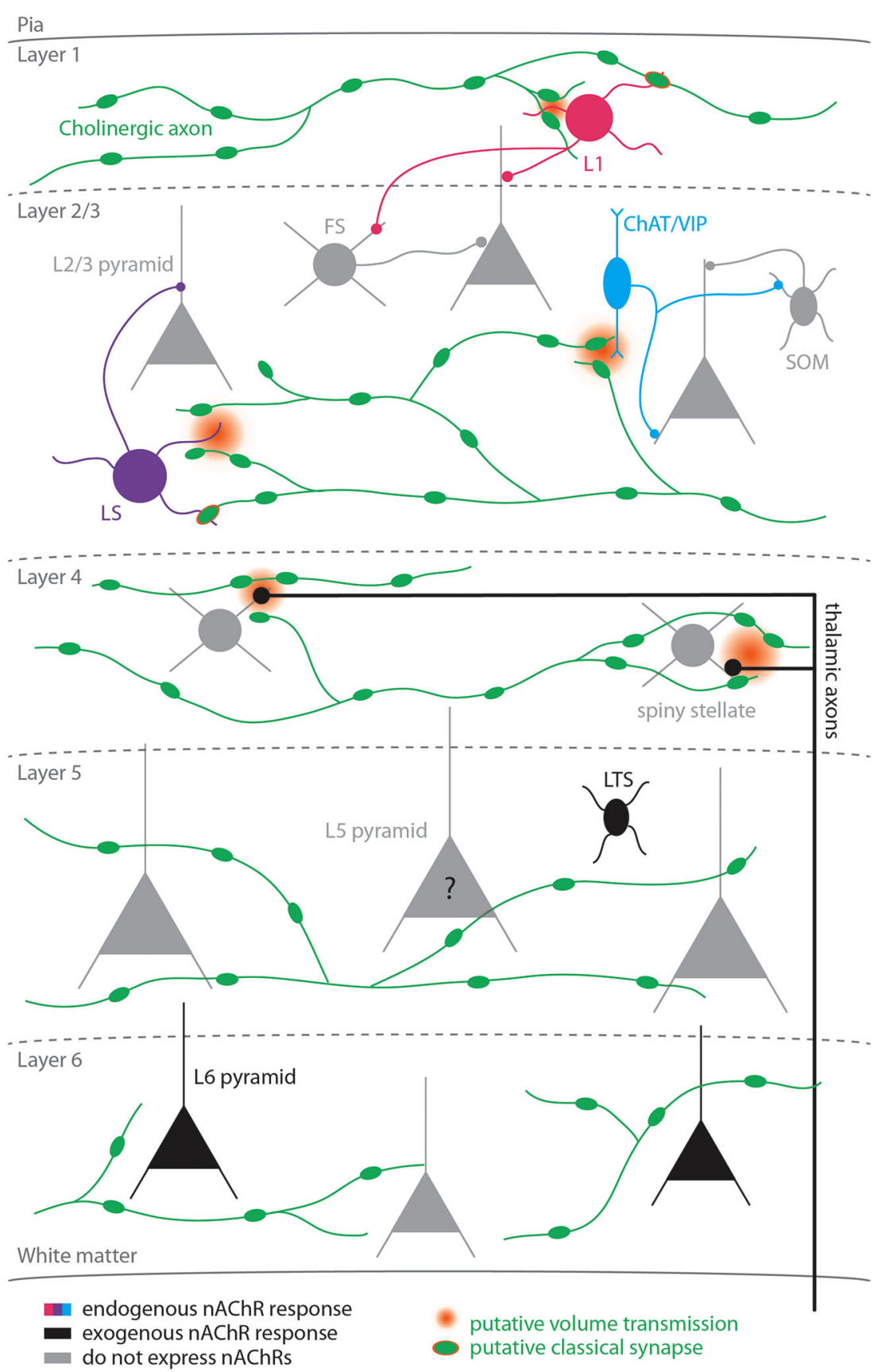

FIGURE 1 | Nicotinic signaling in the cortex. Colored cells represent cell-types known to exhibit nAChR-dependent responses to activation of cholinergic axons; black cells represent cell-types that exhibit nicotinic responses to exogenous application of cholinergic agonists; gray cells represent cell-types that do not express nicotinic receptors. The question mark for L5 pyramidal cells reflects the fact that studies disagree as to whether this cell-type expresses functional nicotinic receptors. Two types of nicotinic signaling are depicted: putative volume transmission targeting non- $\alpha 7$ nAChRs (gradient) and putative classical synapses targeting $\alpha 7$ nAChRs (green symbol with orange border).

\section{BASAL FOREBRAIN (BF) CHOLINERGIC AXONS TARGET SPECIFIC CORTICAL CELL TYPES}

The properties of $\alpha 7$ and non- $\alpha 7$ receptors and their pattern of expression in cortical cells suggest that postsynaptic nicotinic responses may vary in their kinetics. In order to study the properties of nAChR-mediated responses in cortex, it is necessary to record responses to selective activation of cholinergic fibers. Several recent studies have used optogenetic tools to probe cholinergic synapses throughout the brain, including the hippocampus (Gu and Yakel, 2011), thalamus (Sun et al., 2013), interpeduncular nucleus (Ren et al., 2011), and striatum (English et al., 2012). In the cortex, we have recently shown that L1 interneurons, L2/3 
late-spiking (LS) interneurons, and L2/3 choline acetyltransferase (ChAT)-expressing interneurons (a class of cells that also express VIP) exhibit nicotinic responses following photostimulation of channelrhodopsin-2 (ChR2)-expressing BF axons (Arroyo et al., 2012). The endogenous nicotinic response in L1 and L2/3 LS cells was mediated both by $\alpha 7$ and non- $\alpha 7$ nAChRs, while the responses in L2/3 ChAT/VIP-expressing cells exhibited only non$\alpha 7$ receptor responses.

By eliciting endogenous release of ACh from BF cholinergic axons, we were able to characterize the cholinergic synapse in the cortex for the first time and identify the time course of nAChR-mediated responses. Interestingly, the kinetics of the responses mediated by $\alpha 7$ and non- $\alpha 7$ nAChRs differed by an order of magnitude ( $\alpha 7$ : rise time $\sim 3 \mathrm{~ms}$, decay tau $\sim 5 \mathrm{~ms}$; non$\alpha 7$ : rise time $\sim 35 \mathrm{~ms}$, decay tau $\sim 200 \mathrm{~ms}$; Figure $2 \mathrm{~A}$, Arroyo et al., 2012). Although the peak amplitude of the fast $\alpha 7$ response was often larger, more charge was transferred via the slower non$\alpha 7$ response, leading to a slow barrage of disynaptic inhibition in upper layer pyramidal neurons and FS cells (Arroyo et al., 2012).

\section{MECHANISMS UNDERLYING NICOTINIC TRANSMISSION IN THE CORTEX}

Cholinergic cells in the BF project throughout the cortex where they form a dense web of presynaptic varicosities spanning all cortical layers. Numerous anatomical studies observed that a large fraction of these varicosities are not directly adjacent to postsynaptic structures, leading to the hypothesis that the cholinergic system operates primarily by diffuse release of neurotransmitter into the extracellular space ("volume transmission") (Mrzljak et al., 1993; Umbriaco et al., 1994; Lendvai and Vizi, 2008; Yamasaki et al., 2010), though others have emphasized the presence of classical synaptic contacts (Turrini et al., 2001).

The presence of both a slow nicotinic response mediated by the high affinity non- $\alpha 7$ receptor and a fast response mediated by the low affinity $\alpha 7$ receptor (Arroyo et al., 2012) led us to hypothesize that these two response components might be mediated by volume transmission and classical synaptic transmission, respectively. We performed several lines of experiments to test this possibility.

The trial-to-trial variability of synaptic responses depends in part on the number of release sites mediating transmission between presynaptic fibers and the postsynaptic cell (Manabe et al., 1993). Because non-synaptic receptors activated by volume transmission can sample release from many presynaptic sites, this form of signaling should be characterized by low variability (Szapiro and Barbour, 2007). In cells exhibiting dual component excitatory postsynaptic currents (EPSCs; Figure 2A) we found that the response variability of the slow component was severalfold smaller than that of the fast component as quantified by the coefficient of variation (CV; Figures 2B, C, Bennett et al., 2012). Moreover, the amplitudes of the fast and slow response components were not correlated across single trials (Figure 2D). These data are consistent with the notion that the slow response component is mediated by ACh release from many non-synaptic release sites while the fast response component is mediated by relatively fewer release sites onto classical postsynaptic terminals.

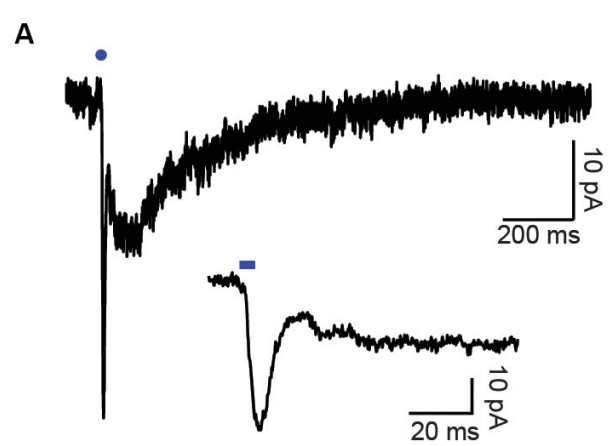

B

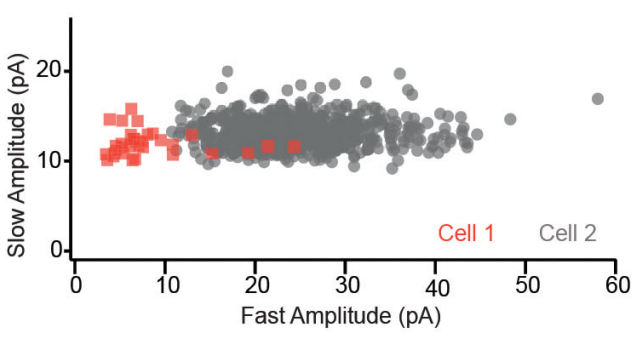

C
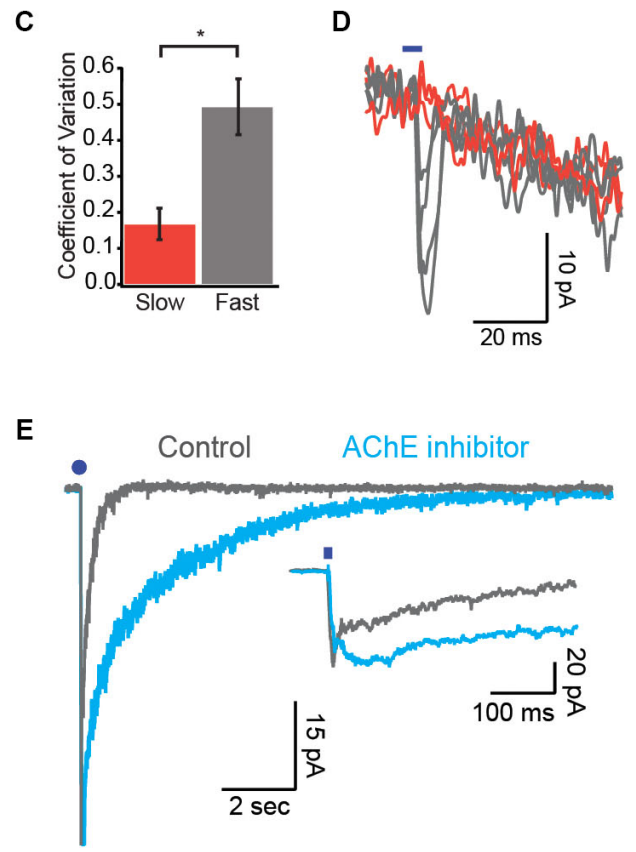

FIGURE 2 | Synaptic mechanisms underlying cholinergic transmission (A) Example dual-component response recorded under voltage clamp. Note the fast $\alpha 7$ mediated response followed by the slower non- $\alpha 7$ response. Inset, fast component is displayed on an expanded timescale. (B) Response amplitude for the slow component is plotted against the response amplitude of the fast component for two cells. Note that the fast component exhibits much more variability in amplitude relative to the slow component. (C) Variability of the two response components quantified as the coefficient of variation (CV). (D) Example single trial responses to photostimulation demonstrate a reliable slow component across trials in which the fast component varied widely. Orange traces represent trials in which a fast component was not detectable. (E) Dual-component nicotinic responses before and after application of the AChE inhibitor ambenonium. Inset, expanded timescale reveals no effect of the AChE blocker on the fast component. Blue circles and ticks represent photostimulation. 
Responses mediated by volume transmission are highly sensitive to perturbations of transmitter clearance (Szapiro and Barbour, 2007). We found that application of an AChE inhibitor drastically prolonged the decay of the slow but not the fast nicotinic response (Figure 2E, Bennett et al., 2012). Moreover, application of exogenous AChE selectively attenuated the slow response (Bennett et al., 2012). Together, these data suggest that the fast and slow nicotinic responses are mediated by distinct synaptic mechanisms.

A conclusive determination of synaptic or non-synaptic transmission requires detailed anatomical reconstruction of receptor localization relative to presynaptic varicosities and a characterization of the kinetics of $\alpha 7$ and non- $\alpha 7$ receptors. To date, no anatomical study has examined the spatial relationship between nicotinic receptor subtypes and cholinergic varicosities in the cortex. Furthermore, though we were able to estimate the kinetics of $\alpha 7$ receptors for a range of ACh concentrations using nucleated patches, we did not observe non- $\alpha 7$ receptor responses in this preparation, and no previous studies report the kinetics of natively expressed non- $\alpha 7$ receptors.

Given the lack of anatomical data, we cannot exclude the possibility that $\alpha 7$ receptors are located perisynaptically and not at classical postsynaptic specializations, since both of these arrangements could produce high variability and insensitivity to AChE perturbation. Similarly, our data do not definitively rule out the possibility that non- $\alpha 7$ receptor-mediated currents are synaptic. However, the synapse mediating this response would have to fulfill several specific criteria. To explain our AChE perturbation results, the synaptic cleft would have to be constructed such that activation of postsynaptic receptors is primarily limited by hydrolysis of ACh by AChE rather than diffusion. This is remarkable given that diffusion of neurotransmitter out of a conventional synaptic cleft is extremely fast (concentration decay $t_{1 / 2} \sim 0.15 \mathrm{~ms}$; Eccles and Jaeger, 1958). Moreover, the slow rise time of the non- $\alpha 7$ receptormediated EPSC (20-80\% in $35 \mathrm{~ms}$ ) would require that these receptors exhibit exceptionally slow activation kinetics. Since both synaptic and nonsynaptic cholinergic varicosities are found in cortex, we believe that a more parsimonious explanation of our data is that non- $\alpha 7$ nicotinic receptors are located extrasynaptically where they bind ACh diffusing from nonsynaptic release sites.

\section{FUNCTIONAL CONSEOUENCES OF NICOTINIC RECEPTOR ACTIVATION IN THE CORTEX}

Numerous studies have demonstrated that activation of nicotinic receptors is critical for normal cognition. Administration of nicotine has been shown to enhance working memory and attention and to alleviate the cognitive deficits observed in multiple neuropsychiatric conditions (Levin, 2002). Furthermore, loss of the $\beta 2$ nAChR subunit, a necessary component of the high affinity non- $\alpha 7$ cortical nAChR ( $\alpha 4 \beta 2)$, has been shown to impair both learning (assayed by a passive avoidance task; Picciotto et al., 1995 ) and attention (assayed by the 5 choice serial reaction time test, 5CSRTT; Cordero-Erausquin et al., 2000; Guillem et al., 2011). Though knockout of the $\alpha 7 \mathrm{nAChR}$ subunit does not affect gross neurological function (Orr-Urtreger et al., 1997) or performance on the 5CSRTT (Grottick and Higgins, 2000; Howe et al., 2010; Guillem et al., 2011), recent evidence suggests that activating $\alpha 7 \mathrm{nAChRs}$ may alleviate the cognitive impairments associated with Alzheimer's disease and schizophrenia (Levin, 2013). Recently, it was shown that optogenetic activation of BF cholinergic axons in visual cortex enhanced performance on a visual discrimination task, while silencing BF cholinergic cells impaired performance (Pinto et al., 2013). However, whether this effect was mediated by nicotinic or muscarinic receptors was not investigated.

Several mechanisms have been proposed to account for the behavioral enhancements associated with nAChR activation. First, it has been suggested nAChR activation may lead to amplification of sensory responses by modulating release from thalamocortical terminals. Indeed, in brain slices preserving thalamocortical connections, it was shown that release from thalamocortical terminals is enhanced by nicotine (Gil et al., 1997). A recent study extended this finding by showing that iontophoresis of nicotine in primate visual cortex augments responses to visual stimuli (Disney et al., 2007). Interestingly, nAChRs are present on thalamocortical axons targeting excitatory but not inhibitory cells in L4 (Disney et al., 2007; Kruglikov and Rudy, 2008), suggesting that ACh may play a role in modulating the balance of excitation and inhibition elicited by sensory stimuli.

Another line of studies suggests that $\mathrm{nAChR}$ activation may shape the spatiotemporal pattern of inhibition in cortex by differentially modulating the excitability of distinct classes of interneurons. Our data demonstrate that activation of cholinergic axons in brain slices elicits disynaptic inhibition in both pyramidal neurons and inhibitory FS cells (Arroyo et al., 2012). This nAChR-dependent inhibition of FS cells is consistent with a recent study showing that cholinergic activation following foot shock inhibits spiking in $\mathrm{L} 2 / 3 \mathrm{PV}+$ neurons in auditory cortex (Letzkus et al., 2011). In this study, the authors show that a fraction of L1 interneurons exhibit a nAChR-dependent increase in spiking after foot shock and suggest that these cells mediate the inhibition observed in PV+ cells; however, whether other nAChR expressing interneurons in L2/3 play a role in mediating cortical disinhibition was not definitively ruled out. Indeed, two recent studies suggest that another population of nAChR-expressing cells, VIP+ interneurons, preferentially target SOM-expressing interneurons in the visual cortex (Pfeffer et al., 2013) and barrel cortex (Lee et al., 2013) and, to a lesser degree, PV+ interneurons (Dávid et al., 2007; Hioki et al., 2013; Pi et al., 2013). Thus, it is likely that $\mathrm{nAChR}$ activation produces disinhibition via both $\mathrm{L} 1$ interneurons (Christophe et al., 2002; Letzkus et al., 2011; Jiang et al., 2013) and L2/3 VIP+ interneurons (Lee et al., 2013; Pfeffer et al., 2013).

The substantial difference in kinetics between $\alpha 7$ and non- $\alpha 7$ nicotinic receptors together with their cell-type specific expression suggests that these two nAChRs may play distinct roles in modulating cortical activity. For example, temporally precise excitation mediated by $\alpha 7$ receptors may synchronize activity in $\alpha 7$-receptor expressing interneurons. In contrast, slow excitation mediated by non- $\alpha 7$ receptors may facilitate modulatory pathways that unfold over longer time scales. Indeed, nAChRexpressing interneurons have been implicated in a number of slow processes, including inhibition mediated by postsynaptic $\mathrm{GABA}_{\mathrm{B}}$ 
receptors (Tamás et al., 2003), reduction of synaptic efficacy by activation of presynaptic $\mathrm{GABA}_{\mathrm{B}}$ receptors (Oláh et al., 2009; Chittajallu et al., 2013), and regulation of cerebral blood flow (Cauli et al., 2004).

\section{FUTURE DIRECTIONS}

Ultimately, understanding how nAChR activation modulates cortical activity will require a more complete understanding of (1) the patterns of activity in cortically projecting cholinergic axons during behavior; (2) the functional roles of nAChRexpressing cortical neurons and their subsequent modulation by endogenously released ACh; and (3) the respective impact of fast and slow nicotinic modulation on cortical circuits. The recent proliferation of Cre-driver lines has allowed investigators to begin to probe the function of various classes of cortical cells, including some cell-types known to express nAChRs. However, further work is needed to uncover how the function of these cortical neurons is modulated by activation/silencing of cholinergic fibers and blockade of specific receptor subtypes. Given the well-established role for nicotinic signaling in numerous neuropsychiatric diseases, a better understanding of the mechanisms underlying nicotinic modulation of cortical activity holds promise for the development of more effective therapeutic interventions.

\section{REFERENCES}

Arroyo, S., Bennett, C., Aziz, D., Brown, S. P., and Hestrin, S. (2012). Prolonged disynaptic inhibition in the cortex mediated by slow, non-alpha7 nicotinic excitation of a specific subset of cortical interneurons. J. Neurosci. 32, 38593864. doi: 10.1523/jneurosci.0115-12.2012

Bennett, C., Arroyo, S., Berns, D., and Hestrin, S. (2012). Mechanisms generating dual-component nicotinic EPSCs in cortical interneurons. J. Neurosci. 32, 17287-17296. doi: 10.1523/jneurosci.3565-12.2012

Cauli, B., Tong, X. K., Rancillac, A., Serluca, N., Lambolez, B., Rossier, J., et al. (2004). Cortical GABA interneurons in neurovascular coupling: relays for subcortical vasoactive pathways. J. Neurosci. 24, 8940-8949. doi: 10.1523/jneurosci. 3065-04.2004

Chittajallu, R., Pelkey, K. A., and Mcbain, C. J. (2013). Neurogliaform cells dynamically regulate somatosensory integration via synapse-specific modulation. Nat. Neurosci. 16, 13-15. doi: 10.1038/nn.3284

Christophe, E., Roebuck, A., Staiger, J. F., Lavery, D. J., Charpak, S., and Audinat, E. (2002). Two types of nicotinic receptors mediate an excitation of neocortical layer I interneurons. J. Neurophysiol. 88, 1318-1327.

Cordero-Erausquin, M., Marubio, L. M., Klink, R., and Changeux, J. P. (2000). Nicotinic receptor function: new perspectives from knockout mice. Trends Pharmacol. Sci. 21, 211-217. doi: 10.1016/s0165-6147(00)01489-9

Dani, J. A., and Bertrand, D. (2007). Nicotinic acetylcholine receptors and nicotinic cholinergic mechanisms of the central nervous system. Annu. Rev. Pharmacol. Toxicol. 47, 699-729. doi: 10.1146/annurev.pharmtox.47.120505. 105214

Dávid, C., Schleicher, A., Zuschratter, W., and Staiger, J. F. (2007). The innervation of parvalbumin-containing interneurons by VIP-immunopositive interneurons in the primary somatosensory cortex of the adult rat. Eur. J. Neurosci. 25, 23292340. doi: 10.1111/j.1460-9568.2007.05496.x

Disney, A. A., Aoki, C., and Hawken, M. J. (2007). Gain modulation by nicotine in macaque v1. Neuron 56, 701-713. doi: 10.1016/j.neuron.2007.09.034

Eccles, J. C., and Jaeger, J. C. (1958). The relationship between the mode of operation and the dimensions of the junctional regions at synapses and motor end-organs. Proc. R. Soc. Lond. B Biol. Sci. 148, 38-56. doi: 10.1098/rspb.1958. 0003

Eckenstein, F. P., Baughman, R. W., and Quinn, J. (1988). An anatomical study of cholinergic innervation in rat cerebral cortex. Neuroscience 25, 457-474. doi: 10. 1016/0306-4522(88)90251-5
English, D. F., Ibanez-Sandoval, O., Stark, E., Tecuapetla, F., Buzsaki, G., Deisseroth, K., et al. (2012). GABAergic circuits mediate the reinforcement-related signals of striatal cholinergic interneurons. Nat. Neurosci. 15, 123-130. doi: 10.1038/nn. 2984

Férézou, I., Cauli, B., Hill, E. L., Rossier, J., Hamel, E., and Lambolez, B. (2002). 5-HT3 receptors mediate serotonergic fast synaptic excitation of neocortical vasoactive intestinal peptide/cholecystokinin interneurons. J. Neurosci. 22, 7389-7397.

Gil, Z., Connors, B. W., and Amitai, Y. (1997). Differential regulation of neocortical synapses by neuromodulators and activity. Neuron 19, 679-686. doi: 10 . 1016/s0896-6273(00)80380-3

Grottick, A. J., and Higgins, G. A. (2000). Effect of subtype selective nicotinic compounds on attention as assessed by the five-choice serial reaction time task. Behav. Brain Res. 117, 197-208. doi: 10.1016/s0166-4328(00) 00305-3

Gu, Z., and Yakel, J. L. (2011). Timing-dependent septal cholinergic induction of dynamic hippocampal synaptic plasticity. Neuron 71, 155-165. doi: 10.1016/j. neuron.2011.04.026

Guillem, K., Bloem, B., Poorthuis, R. B., Loos, M., Smit, A. B., Maskos, U., et al. (2011). Nicotinic acetylcholine receptor beta2 subunits in the medial prefrontal cortex control attention. Science 333, 888-891. doi: 10.1126/science.120 7079

Gulledge, A. T., Park, S. B., Kawaguchi, Y., and Stuart, G. J. (2007). Heterogeneity of phasic cholinergic signaling in neocortical neurons. J. Neurophysiol. 97, 22152229. doi: 10.1152/jn.00493.2006

Hioki, H., Okamoto, S., Konno, M., Kameda, H., Sohn, J., Kuramoto, E., et al. (2013). Cell type-specific inhibitory inputs to dendritic and somatic compartments of parvalbumin-expressing neocortical interneuron. J. Neurosci. 33, 544555. doi: 10.1523/jneurosci.2255-12.2013

Howe, W. M., Ji, J., Parikh, V., Williams, S., Mocaer, E., Trocme-Thibierge, C., et al. (2010). Enhancement of attentional performance by selective stimulation of alpha4beta2 $\left(^{*}\right)$ nAChRs: underlying cholinergic mechanisms. Neuropsychopharmacology 35, 1391-1401. doi: 10.1038/npp.2010.9

Jiang, X., Wang, G., Lee, A. J., Stornetta, R. L., and Zhu, J. J. (2013). The organization of two new cortical interneuronal circuits. Nat. Neurosci. 16, 210 218. doi: $10.1038 / \mathrm{nn} .3305$

Kassam, S. M., Herman, P. M., Goodfellow, N. M., Alves, N. C., and Lambe, E. K. (2008). Developmental excitation of corticothalamic neurons by nicotinic acetylcholine receptors. J. Neurosci. 28, 8756-8764. doi: 10.1523/jneurosci.264508.2008

Kruglikov, I., and Rudy, B. (2008). Perisomatic GABA release and thalamocortical integration onto neocortical excitatory cells are regulated by neuromodulators. Neuron 58, 911-924. doi: 10.1016/j.neuron.2008.04.024

Lee, M. G., Hassani, O. K., Alonso, A., and Jones, B. E. (2005). Cholinergic basal forebrain neurons burst with theta during waking and paradoxical sleep. J. Neurosci. 25, 4365-4369. doi: 10.1523/jneurosci.0178-05. 2005

Lee, S., Hjerling-Leffler, J., Zagha, E., Fishell, G., and Rudy, B. (2010). The largest group of superficial neocortical GABAergic interneurons expresses ionotropic serotonin receptors. J. Neurosci. 30, 16796-16808. doi: 10.1523/jneurosci.186910.2010

Lee, S., Kruglikov, I., Huang, Z. J., Fishell, G., and Rudy, B. (2013). A disinhibitory circuit mediates motor integration in the somatosensory cortex. Nat. Neurosci. 16, 1662-1670. doi: 10.1038/nn.3544

Lendvai, B., and Vizi, E. S. (2008). Nonsynaptic chemical transmission through nicotinic acetylcholine receptors. Physiol. Rev. 88, 333-349. doi: 10. 1152/physrev.00040.2006

Letzkus, J. J., Wolff, S. B., Meyer, E. M., Tovote, P., Courtin, J., Herry, C., et al. (2011). A disinhibitory microcircuit for associative fear learning in the auditory cortex. Nature 480, 331-335. doi: 10.1038/nature10674

Levin, E. D. (2002). Nicotinic receptor subtypes and cognitive function. J. Neurobiol. 53, 633-640. doi: 10.1002/neu.10151

Levin, E. D. (2013). Complex relationships of nicotinic receptor actions and cognitive functions. Biochem. Pharmacol. 86, 1145-1152. doi: 10.1016/j.bcp. 2013.07.021

Manabe, T., Wyllie, D. J., Perkel, D. J., and Nicoll, R. A. (1993). Modulation of synaptic transmission and long-term potentiation: effects on paired pulse facilitation and EPSC variance in the CA1 region of the hippocampus. $J$. Neurophysiol. 70, 1451-1459. 
Mesulam, M. M., Mufson, E. J., Wainer, B. H., and Levey, A. I. (1983). Central cholinergic pathways in the rat: an overview based on an alternative nomenclature (Ch1-Ch6). Neuroscience 10, 1185-1201. doi: 10.1016/03064522(83)90108-2

Mrzljak, L., Levey, A. I., and Goldman-Rakic, P. S. (1993). Association of m1 and $\mathrm{m} 2$ muscarinic receptor proteins with asymmetric synapses in the primate cerebral cortex: morphological evidence for cholinergic modulation of excitatory neurotransmission. Proc. Natl. Acad. Sci. U S A 90, 5194-5198. doi: 10. 1073/pnas.90.11.5194

Oláh, S., Füle, M., Komlosi, G., Varga, C., Baldi, R., Barzo, P., et al. (2009). Regulation of cortical microcircuits by unitary GABA-mediated volume transmission. Nature 461, 1278-1281. doi: 10.1038/nature08503

Orr-Urtreger, A., Goldner, F. M., Saeki, M., Lorenzo, I., Goldberg, L., De Biasi, M., et al. (1997). Mice deficient in the alpha7 neuronal nicotinic acetylcholine receptor lack alpha-bungarotoxin binding sites and hippocampal fast nicotinic currents. J. Neurosci. 17, 9165-9171.

Pfeffer, C. K., Xue, M., He, M., Huang, Z. J., and Scanziani, M. (2013). Inhibition of inhibition in visual cortex: the logic of connections between molecularly distinct interneurons. Nat. Neurosci. 16, 1068-1076. doi: 10.1038/nn.3446

Pi, H. J., Hangya, B., Kvitsiani, D., Sanders, J. I., Huang, Z. J., and Kepecs, A. (2013). Cortical interneurons that specialize in disinhibitory control. Nature 503, 521524. doi: 10.1038/nature12676

Picciotto, M. R., Zoli, M., Lena, C., Bessis, A., Lallemand, Y., Le Novere, N., et al. (1995). Abnormal avoidance learning in mice lacking functional high-affinity nicotine receptor in the brain. Nature 374, 65-67. doi: 10.1038/374065a0

Pinto, L., Goard, M. J., Estandian, D., Xu, M., Kwan, A. C., Lee, S. H., et al. (2013). Fast modulation of visual perception by basal forebrain cholinergic neurons. Nat. Neurosci. 16, 1857-1863. doi: 10.1038/nn.3552

Poorthuis, R. B., Bloem, B., Schak, B., Wester, J., De Kock, C. P., and Mansvelder, H. D. (2013). Layer-specific modulation of the prefrontal cortex by nicotinic acetylcholine receptors. Cereb. Cortex 23, 148-161. doi: 10.1093/cercor/bhr390

Porter, J. T., Cauli, B., Tsuzuki, K., Lambolez, B., Rossier, J., and Audinat, E. (1999). Selective excitation of subtypes of neocortical interneurons by nicotinic receptors. J. Neurosci. 19, 5228-5235.

Ren, J., Qin, C., Hu, F., Tan, J., Qiu, L., Zhao, S., et al. (2011). Habenula "cholinergic" neurons co-release glutamate and acetylcholine and activate postsynaptic neurons via distinct transmission modes. Neuron 69, 445-452. doi: 10.1016/j. neuron.2010.12.038

Rieck, R., and Carey, R. G. (1984). Evidence for a laminar organization of basal forebrain afferents to the visual cortex. Brain Res. 297, 374-380. doi: 10. 1016/0006-8993(84)90579-1

Rye, D. B., Wainer, B. H., Mesulam, M. M., Mufson, E. J., and Saper, C. B. (1984). Cortical projections arising from the basal forebrain: a study of cholinergic and noncholinergic components employing combined retrograde tracing and immunohistochemical localization of choline acetyltransferase. Neuroscience 13, 627-643. doi: 10.1016/0306-4522(84)90083-6

Saper, C. B. (1984). Organization of cerebral cortical afferent systems in the rat. II. Magnocellular basal nucleus. J. Comp. Neurol. 222, 313-342. doi: 10.1002/cne. 902220302
Sun, Y. G., Pita-Almenar, J. D., Wu, C. S., Renger, J. J., Uebele, V. N., Lu, H. C., et al. (2013). Biphasic cholinergic synaptic transmission controls action potential activity in thalamic reticular nucleus neurons. J. Neurosci. 33, 20482059. doi: 10.1523/jneurosci.3177-12.2013

Szapiro, G., and Barbour, B. (2007). Multiple climbing fibers signal to molecular layer interneurons exclusively via glutamate spillover. Nat. Neurosci. 10, 735742. doi: 10.1038/nn1907

Tamás, G., Lorincz, A., Simon, A., and Szabadics, J. (2003). Identified sources and targets of slow inhibition in the neocortex. Science 299, 1902-1905. doi: 10. 1126/science. 1082053

Turrini, P., Casu, M. A., Wong, T. P., De Koninck, Y., Ribeiro-Da-Silva, A., and Cuello, A. C. (2001). Cholinergic nerve terminals establish classical synapses in the rat cerebral cortex: synaptic pattern and age-related atrophy. Neuroscience 105, 277-285. doi: 10.1016/s0306-4522(01)00172-5

Umbriaco, D., Watkins, K. C., Descarries, L., Cozzari, C., and Hartman, B. K. (1994). Ultrastructural and morphometric features of the acetylcholine innervation in adult rat parietal cortex: an electron microscopic study in serial sections. J. Comp. Neurol. 348, 351-373. doi: 10.1002/cne.903480304

Winzer-Serhan, U. H., and Leslie, F. M. (2005). Expression of alpha5 nicotinic acetylcholine receptor subunit mRNA during hippocampal and cortical development. J. Comp. Neurol. 481, 19-30. doi: 10.1002/cne.20357

Wu, M. F., John, J., Boehmer, L. N., Yau, D., Nguyen, G. B., and Siegel, J. M. (2004). Activity of dorsal raphe cells across the sleep-waking cycle and during cataplexy in narcoleptic dogs. J. Physiol. 554, 202-215. doi: 10.1113/jphysiol.2003.052134

Xiang, Z., Huguenard, J. R., and Prince, D. A. (1998). Cholinergic switching within neocortical inhibitory networks. Science 281, 985-988. doi: 10.1126/science.281. 5379.985

Yamasaki, M., Matsui, M., and Watanabe, M. (2010). Preferential localization of muscarinic M1 receptor on dendritic shaft and spine of cortical pyramidal cells and its anatomical evidence for volume transmission. J. Neurosci. 30, 4408-4418. doi: 10.1523/jneurosci.5719-09.2010

Zolles, G., Wagner, E., Lampert, A., and Sutor, B. (2009). Functional expression of nicotinic acetylcholine receptors in rat neocortical layer 5 pyramidal cells. Cereb. Cortex 19, 1079-1091. doi: 10.1093/cercor/bhn158

Conflict of Interest Statement: The authors declare that the research was conducted in the absence of any commercial or financial relationships that could be construed as a potential conflict of interest.

Received: 16 January 2014; accepted: 10 March 2014; published online: 28 March 2014. Citation: Arroyo S, Bennett C and Hestrin S (2014) Nicotinic modulation of cortical circuits. Front. Neural Circuits 8:30. doi: 10.3389/fncir.2014.00030

This article was submitted to the journal Frontiers in Neural Circuits.

Copyright (c) 2014 Arroyo, Bennett and Hestrin. This is an open-access article distributed under the terms of the Creative Commons Attribution License (CC BY). The use, distribution or reproduction in other forums is permitted, provided the original author(s) or licensor are credited and that the original publication in this journal is cited, in accordance with accepted academic practice. No use, distribution or reproduction is permitted which does not comply with these terms. 